\title{
The Atmospheric-Pressure Plasma Jet: A Review and Comparison to Other Plasma Sources
}

\author{
Andreas Schütze, James Y. Jeong, Steven E. Babayan, Jaeyoung Park, Gary S. Selwyn, and Robert F. Hicks
}

\author{
(Invited Paper)
}

\begin{abstract}
Atmospheric-pressure plasmas are used in a variety of materials processes. Traditional sources include transferred arcs, plasma torches, corona discharges, and dielectric barrier discharges. In arcs and torches, the electron and neutral temperatures exceed $3000^{\circ} \mathrm{C}$ and the densities of charge species range from $10^{16}-10^{19} \mathrm{~cm}^{-3}$. Due to the high gas temperature, these plasmas are used primarily in metallurgy. Corona and dielectric barrier discharges produce nonequilibrium plasmas with gas temperatures between $50-400{ }^{\circ} \mathrm{C}$ and densities of charged species typical of weakly ionized gases. However, since these discharges are nonuniform, their use in materials processing is limited. Recently, an atmospheric-pressure plasma jet has been developed, which exhibits many characteristics of a conventional, low-pressure glow discharge. In the jet, the gas temperature ranges from $25-200^{\circ} \mathrm{C}$, charged-particle densities are $10^{11}-10^{12}$ $\mathrm{cm}^{-3}$, and reactive species are present in high concentrations, i.e., 10-100 ppm. Since this source may be scaled to treat large areas, it could be used in applications which have been restricted to vacuum. In this paper, the physics and chemistry of the plasma jet and other atmospheric-pressure sources are reviewed.
\end{abstract}

Index Terms-Atmospheric pressure, corona discharge, dielectric barrier discharge, plasma jet, plasma torch, thermal and nonthermal plasmas, transferred arc.

\section{INTRODUCTION}

$\mathbf{L}$ OW-PRESSURE plasmas have found wide applications in materials processing and play a key role in manufacturing semiconductor devices [1], [2]. The advantages of plasmas are well known. They generate high concentrations of reactive species that can etch and deposit thin films at rates up to $10 \mu \mathrm{m} / \mathrm{min}$. The temperature of the gas is usually below $150^{\circ} \mathrm{C}$, so that thermally sensitive substrates are not damaged. The ions produced in the plasma can be accelerated toward a substrate to cause directional etching of submicron features. In addition, a uniform glow discharge can be generated, so

Manuscript received March 30, 1998. This work was supported in part by the U.S. Department of Energy, the University of California, the Basic Energy Sciences, Environmental Management Sciences Program, and the Office of Science and Risk Policy under Award DE-F5607-96ER45621. The work of A. Schütze was supported by a fellowship from the Deutsche Forschungsgemeinschaft (DFG). The work of J. Y. Jeong and S. E. Babayan and was supported by fellowships from the University of California Center for Environmental Risk Reduction and the Toxic Substances Research and Training Program.

A. Schütze, J. Y. Jeong, S. E. Babayan, and R. F. Hicks are with the Department of Chemical Engineering, University of California, Los Angeles, CA 90095-1592 USA (e-mail: schuetze@seas.ucla.edu).

J. Park and G. S. Selwyn are with Los Alamos National Laboratory, Los Alamos, NM 87545 USA.

Publisher Item Identifier S 0093-3813(98)09643-X. that materials processing proceeds at the same rate over large substrate areas. On the other hand, operating the plasma at reduced pressure has several drawbacks. Vacuum systems are expensive and require maintenance. Load locks and robotic assemblies must be used to shuttle materials in and out of vacuum. Also, the size of the object that can be treated is limited by the size of the vacuum chamber.

Atmospheric-pressure plasmas overcome the disadvantages of vacuum operation. However, the difficulty of sustaining a glow discharge under these conditions leads to a new set of challenges. Higher voltages are required for gas breakdown at 760 torr, and often arcing occurs between the electrodes. In some applications, such as plasma torches, arcing is intentionally sought [3], [4]. However, to prevent arcing and lower the gas temperature, several schemes have been devised, such as the use of pointed electrodes in corona discharges [5] and insulating inserts in dielectric barrier discharges [6]. A drawback of these sources is that the plasmas are not uniform throughout the volume. Recently, a plasma jet has been developed which uses flowing helium and a special electrode design to prevent arcing [7]. This source can etch and deposit materials at low temperatures and may be suitable for a wide range of applications.

A number of review articles have been published on atmospheric-pressure plasmas [3], [4], [6], [8], [9]. However, these articles are devoted to either thermal, or nonthermal sources, and do not include recent advances in the field. In this paper, we give an overview of these plasma sources and highlight the recent development of the atmospheric-pressure plasma jet. First, we consider the effect of pressure on the physical properties of plasmas. Then in the following sections, each atmospheric-pressure source is examined. Topics of interest include the current-voltage characteristics, electron and neutral temperatures, densities of charged particles, and gas compositions for oxygen-based systems. Finally, in the last section, a quantitative comparison is made between traditional sources and the atmospheric-pressure plasma jet.

\section{Properties of Plasmas}

To ignite a plasma, the breakdown-voltage $V_{b}$ for the gas must be exceeded. This voltage depends on the electrode spacing $d$ and the pressure $p$ as follows [2], [8], [10]:

$$
V_{b}=\frac{B(p \cdot d)}{\ln [A(p \cdot d)]-\ln \left[\ln \left(1+1 / \gamma_{s e}\right)\right]} .
$$




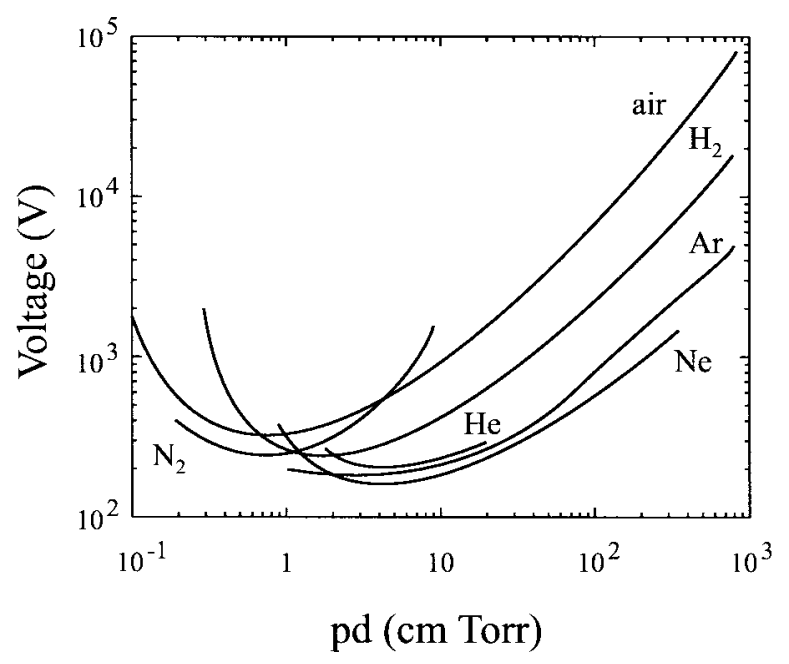

Fig. 1. Breakdown potential in various gases as a function of the pressure and gap distance $p \times d$ for plane-parallel electrodes [8].

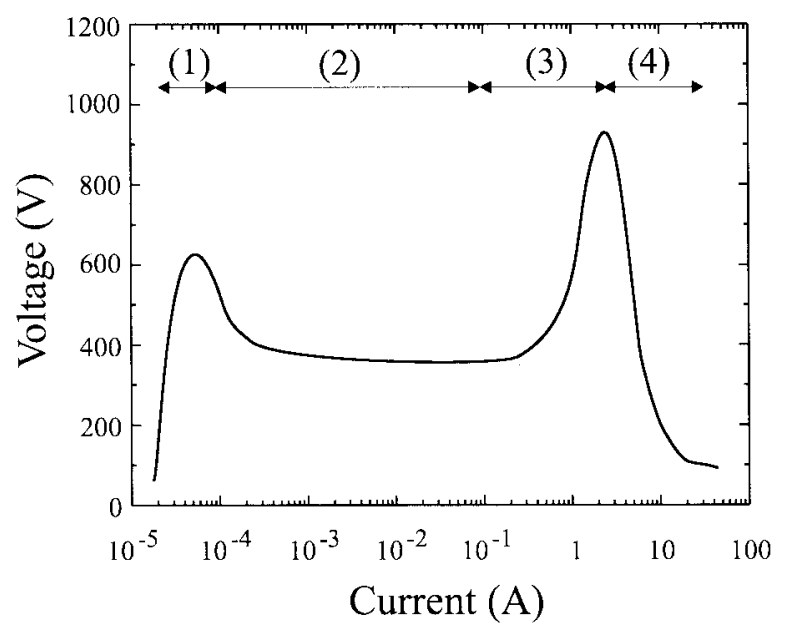

Fig. 2. Current-voltage characteristics of a low-pressure DC glow discharge at 1 torr [13].

Here, $A$ and $B$ are constants found experimentally, and $\gamma_{s e}$ is the secondary electron emission coefficient of the cathode. Paschen curves, showing the dependence of the breakdown voltage on electrode spacing and pressure, are presented in Fig. 1, [8], [11], and [12]. Above $p \times d=10, V_{b}$ increases rapidly with pressure at a constant electrode spacing. For example, the breakdown voltage for argon is estimated to be $2500 \mathrm{~V}$ at 760 torr and with a $5 \mathrm{~mm}$ gap distance. A narrow gap is necessary to achieve a reasonable breakdown voltage at atmospheric pressure.

Insight into the operation of a plasma can be obtained from the dependence of the applied voltage on current. This relationship is illustrated in Fig. 2 for a low-pressure DC glow discharge [13]. The discharge can be divided into four regions: 1) the "dark" or "Townsend discharge" prior to spark ignition; 2) "normal glow" where the voltage is constant or slightly decreasing with current; 3) "abnormal glow" where the voltage increases with current; and 4) "arc discharge" where the plasma becomes highly conductive. Low-pressure plasmas used in materials processing are operated in region

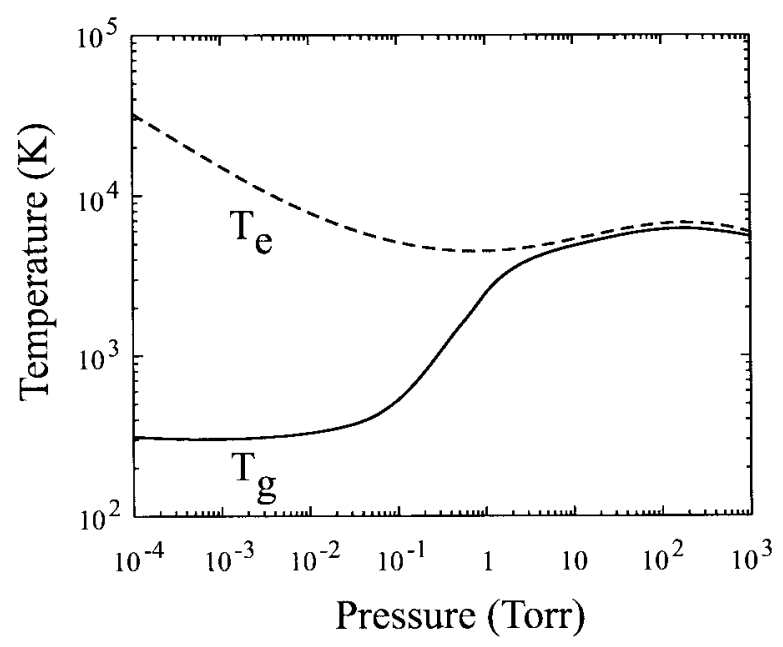

Fig. 3. Schematic of the electron and gas temperature as a function of pressure in a plasma discharge at constant current [14].

2). Regions 2) and 3) tend to shrink with increasing pressure, so that for many gases, spark ignition proceeds directly to arcing at 760 torr.

In a weakly ionized gas at low pressure, the electron density ranges between $10^{8}-10^{13} \mathrm{~cm}^{-3}$ [2]. Under these conditions, the collision rate between electrons and neutral molecules is insufficient to bring about thermal equilibrium. Consequently, the electron temperature $T_{e}$ can be one to two orders of magnitude higher than the neutral and ion temperatures $T_{n}$ and $T_{i}$. However, as the pressure increases, the collision rate will rise to a point where effective energy exchange occurs between the electrons and neutral molecules, so that $T_{e} \approx T_{n}$. In this case, the electron density usually ranges from $10^{16}-10^{19}$ $\mathrm{cm}^{-3}[2]$.

The trend in electron and neutral temperatures with pressure is illustrated in Fig. 3 for a plasma discharge with a mercury and rare gas mixture [14], [15]. At 1 mtorr, the gas temperature is $300 \mathrm{~K}$, while the electron temperature is $10000 \mathrm{~K}(1 \mathrm{eV}=$ $11600 \mathrm{~K})$. These two temperatures merge together above 5 torr to an average value of about $5000 \mathrm{~K}$. Since the probability for energy exchange upon collision of an electron and molecule depends on the nature of the molecule, the pressure at which $T_{g}$ approaches $T_{e}$ should be a sensitive function of the gas composition. For example, there may be compositions where $T_{e}$ and $T_{g}$ merge together above 760 torr.

Shibata et al. [16] have simulated the distribution of reactive species within a parallel-plate oxygen discharge using a relaxation-continuum model. Shown in Fig. 4 are the results obtained during half of the RF cycle with the cathode at $x=0$. The conditions are 0.15 torr $\mathrm{O}_{2}$ pressure, $200 V_{\text {rms }}$ power, and a $20 \mathrm{~mm}$ gap spacing. The simulation shows that the density of charged species varies over a broad range, from $10^{8}-10^{10} \mathrm{~cm}^{-3}$, depending on position. On the other hand, the concentrations of oxygen atoms and metastable oxygen molecules $\left(a^{1} \Delta_{g}\right)$ are much higher, equal to about 0.2 and 2.0 $\times 10^{13} \mathrm{~cm}^{-3}$, respectively. The concentration of metastable oxygen is constant across the gap, whereas the concentration of $\mathrm{O}$ atoms falls to zero at the walls due to surface recombination [16]. This simulation is in good agreement with another 


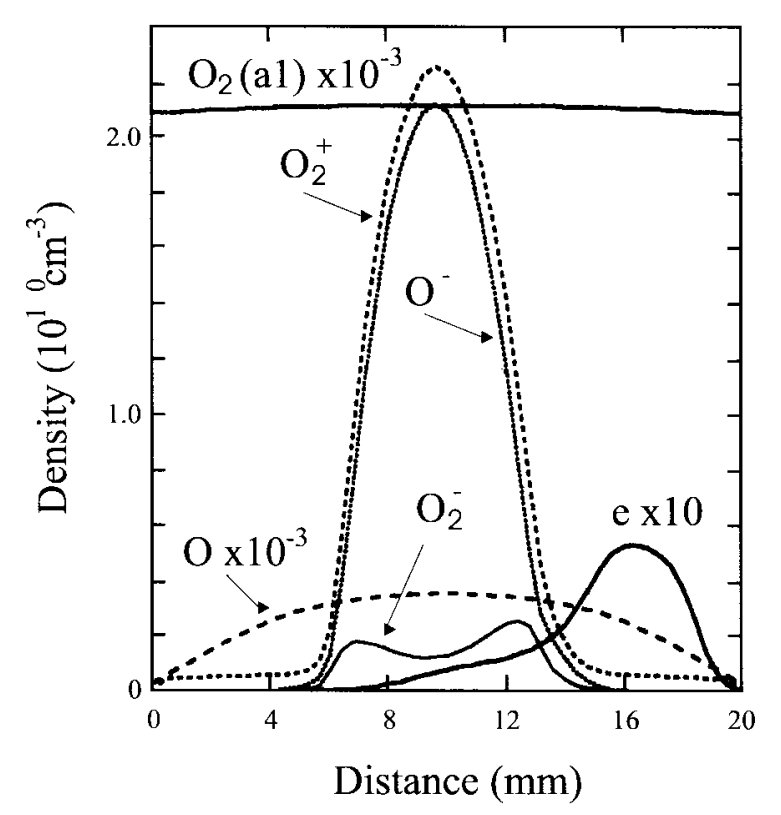

Fig. 4. Spatial particle distributions in a parallel plate $\mathrm{O}_{2} \mathrm{RF}$ discharge at $\omega t=\pi / 2$ for $V_{\mathrm{rms}}=200 \mathrm{~V}[16]$.

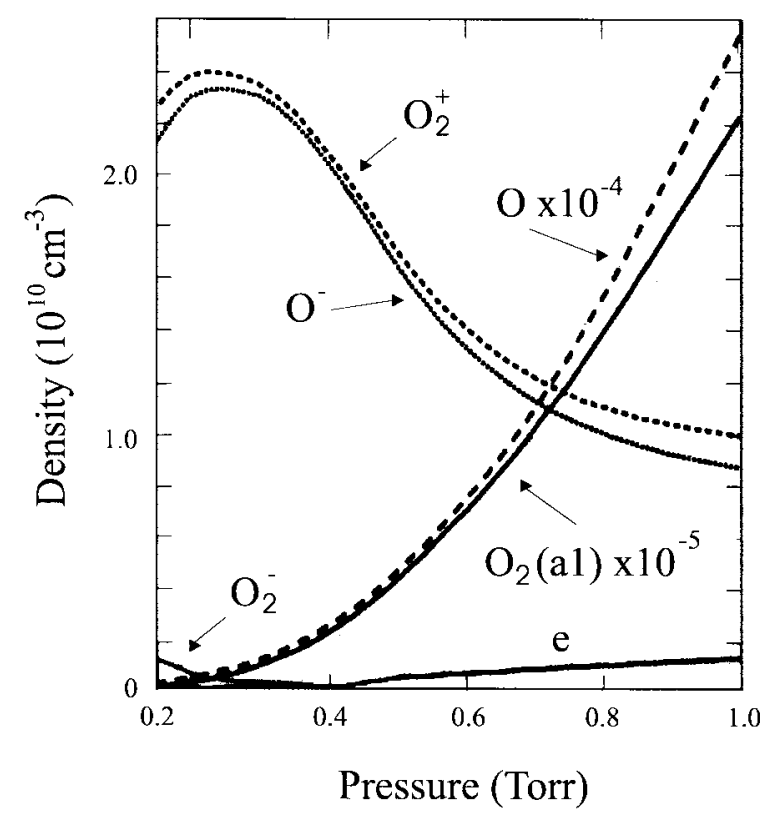

Fig. 5. Time-averaged number densities of each particle in the center of the discharge as a function of pressure in the range between 0.15 and 1 torr [16].

modeling study by Klopovskii et al. [17]. By comparison, Selwyn [18] measured the $\mathrm{O}$ atom concentration in an oxygen and argon RF discharge using two-photon laser excitation. He detected $\mathrm{O}$ atom concentrations of about $5 \times 10^{13} \mathrm{~cm}^{-3}$ at 0.1 torr $\mathrm{O}_{2}$, having a gap distance between two plane electrodes of $55 \mathrm{~mm}$ and a self bias of $300 \mathrm{~V}$.

Shown in Fig. 5 is the effect of pressure on the plasma composition as predicted by Shibata's model. As the pressure increases above 0.3 torr, the density of ions diminishes due to the lower electron energies at higher pressure (cf. Fig. 3), and thus, a lower production rate of ion-electron pairs. On

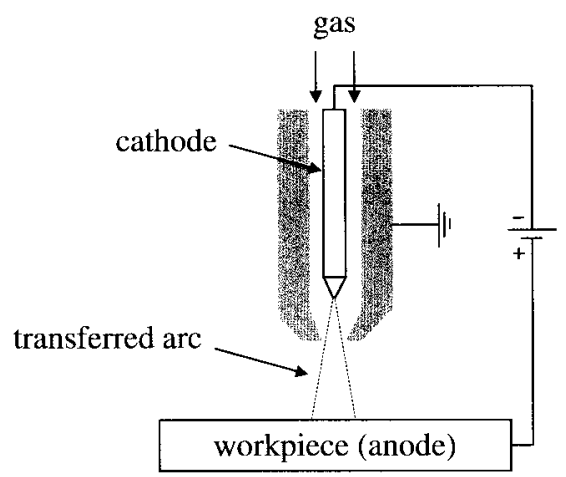

Fig. 6. Schematic of a transferred arc apparatus.

the other hand, the concentrations of $\mathrm{O}_{2}$ metastables and $\mathrm{O}$ atoms increases with pressure, because these species are created by the excitement and dissociation of $\mathrm{O}_{2}$, which requires electron energies of only $1-5 \mathrm{eV}$. The trends shown in Fig. 5 suggest that at atmospheric pressure, ions will be relatively insignificant, so that the chemistry will be dominated by reactive neutral species. In the case of oxygen plasmas, these species are $\mathrm{O}$ atoms, metastable $\mathrm{O}_{2}$, and $\mathrm{O}_{3}$.

\section{TRAnSFERred ARCS AND Plasma Torches}

Transferred arcs are used to cut [3], [4], [19], and [20], melt [4] and [21], and weld condensed materials. A schematic of such a device is shown in Fig. 6. It consists of a cylindrical shaped cathode, an outer grounded and water-cooled shield, and a workpiece as the anode. By feeding argon and hydrogen, oxygen, or air between the cathode and shield, and by applying DC power of up to $200 \mathrm{~kW}$, an arc between the electrodes may be ignited and sustained. Typical operation conditions and properties are 1-15 1/s gas flow, 50-600 A, $10^{4} \mathrm{MW} / \mathrm{m}^{2}$, gas temperatures between 3000 and $20000 \mathrm{~K}$, and a nozzle-tosample distance of 5-10 mm [19]-[22]. These parameters may vary, depending on the nozzle diameter and materials to be cut. Transferred arcs can slice steel plates up to $150 \mathrm{~mm}$ thick. For example, a plate, $40 \mathrm{~mm}$ thick, was cut at $0.7 \mathrm{~m} / \mathrm{min}$ with a $600 \mathrm{~A}$ arc [23].

Several design variations on the transferred arc have been developed. A plasma arc heater uses the shield as the anode instead of the workpiece. In addition, RF induction coils and advanced gas injection schemes are sometimes employed to enhance the plasma density and to restrict the cutting area [9].

Plasma torches are the same as plasma arc heaters, except that they contain a port for injecting precursor compounds that are used in thin film deposition [3], [24]-[26]. In the literature, this technique is also referred to as "injection plasma processing" [25]. The precursors, in the form of solid pellets, powder, or volatile molecules, are introduced just downstream of the arc, where they are vaporized and/or dissociated into reactive species. The resultant mixture is sprayed onto a substrate, thereby coating it with a film at rates up to 10 $\mu \mathrm{m} / \mathrm{min}$. Films which have been deposited with plasma torches include $\mathrm{SiC}$ [26], $\mathrm{SiN}$ [27], $\mathrm{TiO}_{2}$ [28], $\mathrm{Y}-\mathrm{Ba}-\mathrm{Cu}-\mathrm{O}$ [24], [29], $\mathrm{Al}_{2} \mathrm{O}_{3}$ [30], and diamond [31]-[36]. The main purpose of these coatings is to provide materials with added resistance to wear, 


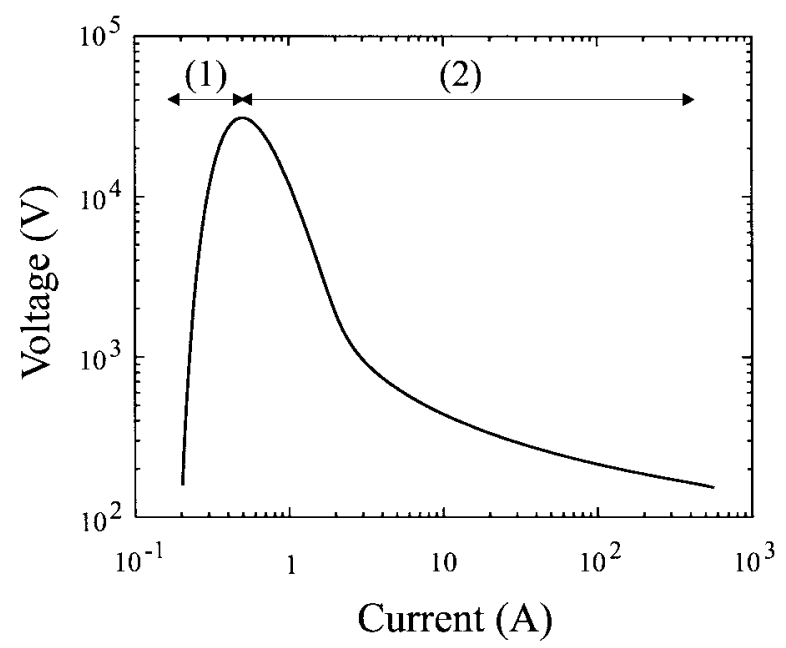

Fig. 7. Current-voltage characteristics of an atmospheric-pressure arc.

corrosion, and oxidation and may also have applications in electrical and electronic fields [37].

Fig. 7 shows the current-voltage characteristics of a plasma torch. After exceeding the breakdown voltage (the maximum in the curve), the gas becomes highly ionized and conductive. This produces a rapid drop in voltage with increasing current. Notice that $300 \mathrm{kV}$ is required to achieve breakdown, whereas at normal operating currents of 200-600 A, only about $100 \mathrm{~V}$ is needed to sustain the arc [19], [38].

Although plasma torches have been considered to be in equilibrium, Kruger et al. [39], [40] have shown that this is not normally the case. With regard to thermal equilibrium, Kim et al. [41] measured the electron and ion temperatures in a plasma torch as a function of the radial and axial positions. They found that $T_{e}$ varied from $7.0-9.0 \mathrm{eV}$, while $T_{i}$ was an order of magnitude lower at $0.3-0.9 \mathrm{eV}$. In addition, they observed electron densities near $3 \times 10^{17} \mathrm{~cm}^{-3}$.

In transferred arcs and plasma torches, extremely high temperatures promote the complete dissociation of the feed gas. For example, Fig. 8 shows the effect of the gas temperature on the distribution of oxygen species and electrons in an arc at $0.95 \mathrm{~atm}$ of oxygen [42]. The oxygen molecules are approximately $99 \%$ dissociated with predominantly all of these molecules being converted into $\mathrm{O}$ atoms. By contrast, the concentrations of $\mathrm{O}_{2}^{+}, \mathrm{O}^{+}$, and $\mathrm{O}^{-}$are several orders of magnitude lower. These results are consistent with the energies required to dissociate and ionize oxygen: $E_{D}\left(\mathrm{O}_{2}\right)=5.11 \mathrm{eV}$, $E_{D}\left(\mathrm{O}_{2}^{+}\right)=6.48 \mathrm{eV}$, and $E_{I}(\mathrm{O})=13.62 \mathrm{eV}[43]$.

\section{CORONA Discharge}

A corona discharge appears as a luminous glow localized in space around a point tip in a highly nonuniform electric field. The physics of this source is well understood [5], [8], [12], [44]-[47]. The corona may be considered a Townsend discharge or a negative glow discharge depending upon the field and potential distribution [45]. Fig. 9 shows a schematic of a point-to-plane corona. The apparatus consists of a metal tip, with a radius of about $3 \mu \mathrm{m}$, and a planar electrode separated from the tip by a distance of $4-16 \mathrm{~mm}$ [47]. The

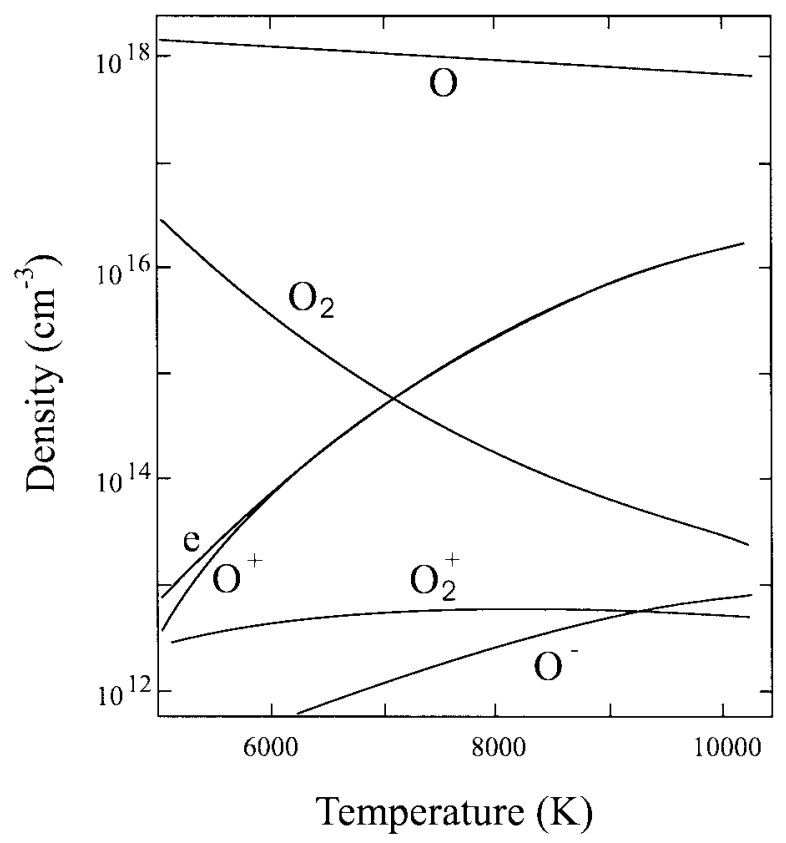

Fig. 8. Composition of an oxygen plasma arc at $0.95 \mathrm{~atm}$ as a function of the temperature [42].

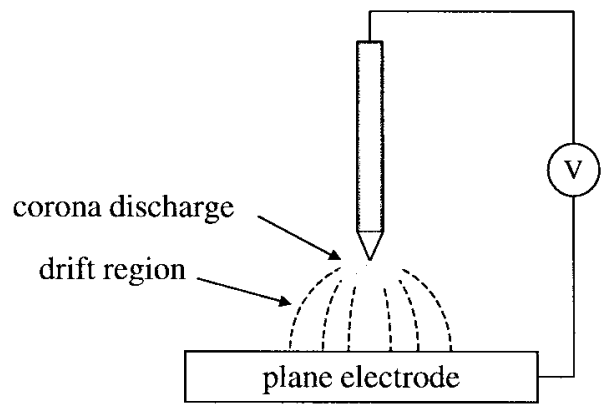

Fig. 9. Schematic of a corona discharge.

plasma usually exists in a region of the gas extending about 0.5 $\mathrm{mm}$ out from the metal point. In the drift region outside this volume, charged species diffuse toward the planar electrode and are collected.

The restricted area of the corona discharge has limited its applications in materials processing. In an attempt to overcome this problem, two-dimensional arrays of electrodes have been developed. Some applications of coronas include the activation of polymer surfaces [48], [49], and the enhancement of $\mathrm{SiO}_{2}$ growth during the thermal oxidation of silicon wafers [50], [51].

Shown in Fig. 10 is the dependence of the voltage on the current for a positive point-to-plane corona operating in air at 760 torr [5], [52]. The plasma ignites at a voltage of 2-5 $\mathrm{kV}$ and produces an extremely small current of $10^{-10^{-}}-10^{-5} \mathrm{~A}$. Above $10^{-5} \mathrm{~A}$, the voltage rapidly increases with current. This coincides with the generation of micro-arcs, or "streamers," that extend between the electrodes. A maximum voltage is recorded at about $5 \times 10^{-4} \mathrm{~A}$, where the device begins to arc. Coronas are operated at currents below the onset of arcing. 


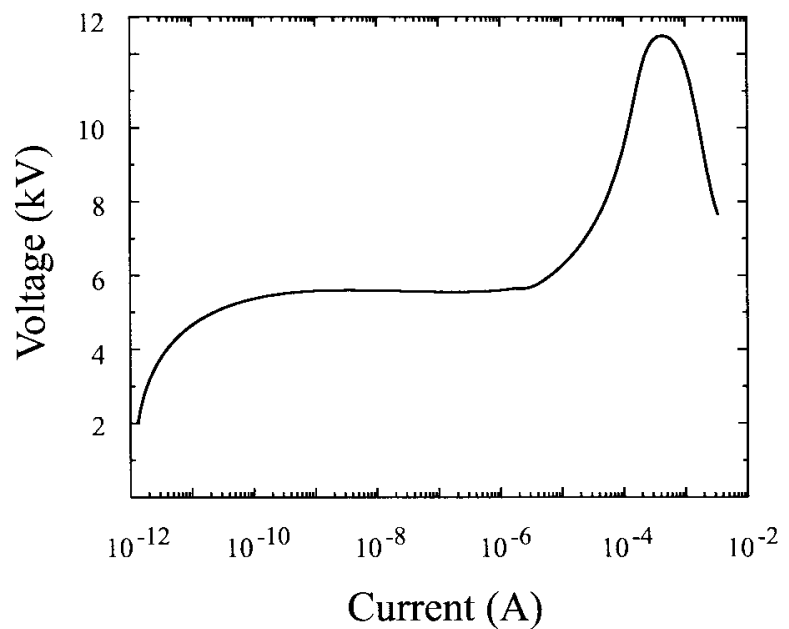

Fig. 10. Current-voltage characteristics for a positive point-to-plane corona discharge with a gap of $13 \mathrm{~mm}$ in $1 \mathrm{~atm}$ of air [5].

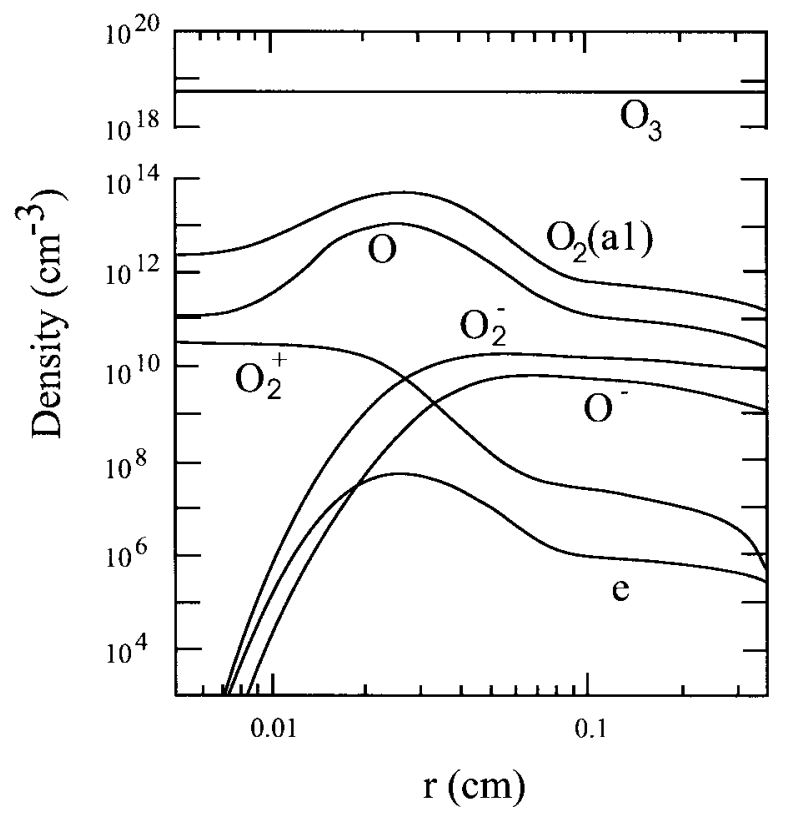

Fig. 11. Concentrations of species in a corona discharge as a function of the radial distance between the electrodes for a potential difference of $V=4.25$ $\mathrm{kV}$ [53].

In the plasma near the tip, the density of charged species rapidly decreases with distance from about $10^{13}-10^{9} \mathrm{~cm}^{-3}$ [5], [8]. The electron temperature within the plasma averages about $5 \mathrm{eV}$. In the drift region outside the discharge, the electron density is much lower, near $10^{6} \mathrm{~cm}^{-3}$.

Pontiga et al. [53] have modeled the distribution of species within a negative corona discharge, operating with pure oxygen at 760 torr and an applied voltage of $4.25 \mathrm{kV}$. His model is based on a discharge between two coaxial electrodes, a wire cathode, and an outer cylinder. Fig. 11 shows the concentration of these species as a function of the radial distance. Ozone is the dominant product at a concentration of $5 \times 10^{18}$ $\mathrm{cm}^{-3}$. Metastable oxygen molecules and $\mathrm{O}$ atoms are five to six orders of magnitude lower in concentration. The ionized

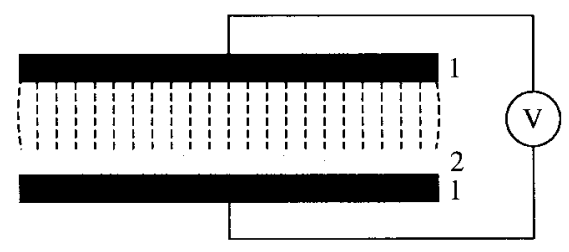

Fig. 12. Schematic of a silent discharge; (1) metallic electrodes and (2) dielectric barrier coating.

species are still lower at an average density of about $10^{10}$ $\mathrm{cm}^{-3}$. This distribution of reaction products differs greatly from that seen in a low-pressure glow discharge (cf. Figs. 4 and 5).

\section{DIELECTRIC BARRIER DISCHARGE}

Dielectric barrier discharges are also called "silent" and "atmospheric-pressure-glow" discharges [6], [54]-[56]. A schematic of this source is shown in Fig. 12. It consists of two metal electrodes, in which at least one is coated with a dielectric layer. The gap is on the order of several $\mathrm{mm}$, and the applied voltage is about $20 \mathrm{kV}$. The plasma is generated through a succession of micro arcs, lasting for 10-100 ns, and randomly distributed in space and time. These streamers are believed to be $\sim 100 \mu \mathrm{m}$ in diameter and are separated from each other by as much as $2 \mathrm{~cm}$ [6], [56]. Dielectric barrier discharges are sometimes confused with coronas, because the latter sources may also exhibit microarcing.

Dielectric barrier discharges have been examined for several material processes, including the cleaning of metal surfaces [57] and the plasma-assisted chemical vapor deposition of polymers [56] and glass films [58]. However, since the plasma is not uniform, its use in etching and deposition is limited to cases where the surface need not be smooth. For example, in the study of $\mathrm{SiO}_{2}$ deposition, it was found that the surface roughness exceeded $10 \%$ of the film thickness [58].

Eliasson and coworkers [6], [54] have modeled silent discharges and have concluded that the electron temperature ranges from $1-10 \mathrm{eV}$. They have also simulated air and oxygen discharges, and their results for pure oxygen at 760 torr are shown in Fig. 13. The $x$ axis is time following the ignition of a single micro arc, and the $y$ axis is the concentration relative to the initial amount of oxygen $\sim 2 \times 10^{19} \mathrm{~cm}^{-3}$. Eliasson's model predicts that the electrons and ions exist for a very short time, from 2-100 ns. These charged species produce $\mathrm{O}$ atoms, which in turn react with oxygen molecules to produce ozone. Beyond about $20 \mathrm{~ms}$, the discharge achieves a steady-state production of ozone of $0.1 \%$ of the initial oxygen density. Silent discharges are efficient ozone generators, and this has proven to be their principal industrial application [6].

\section{PLASMA JET}

Shown in Fig. 14 is a schematic of an atmospheric-pressure plasma jet [7], [59]. This new source consists of two concentric electrodes through which a mixture of helium, oxygen, and other gases flow. By applying 13.56 $\mathrm{MHz} \mathrm{RF}$ power to the inner electrode at a voltage between $100-250 \mathrm{~V}$, the gas discharge is ignited. 


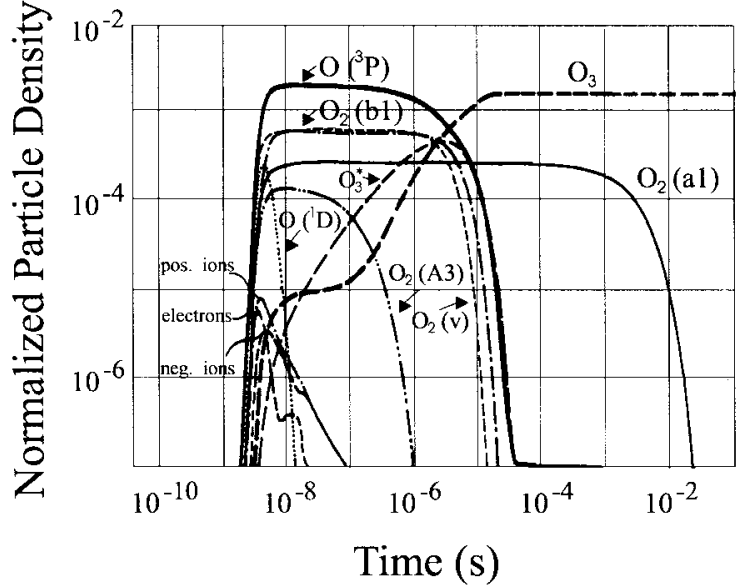

Fig. 13. Numerical simulation of the concentrations of species in a silent discharge in pure oxygen as a function of time at 760 torr and 300K [54].

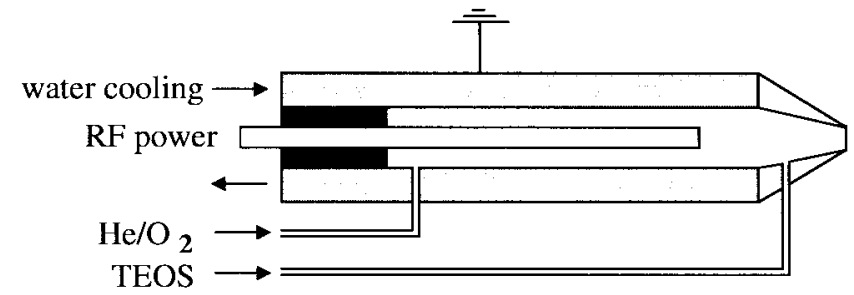

Fig. 14. Schematic of the atmospheric-pressure plasma jet for the deposition of silica films [59].

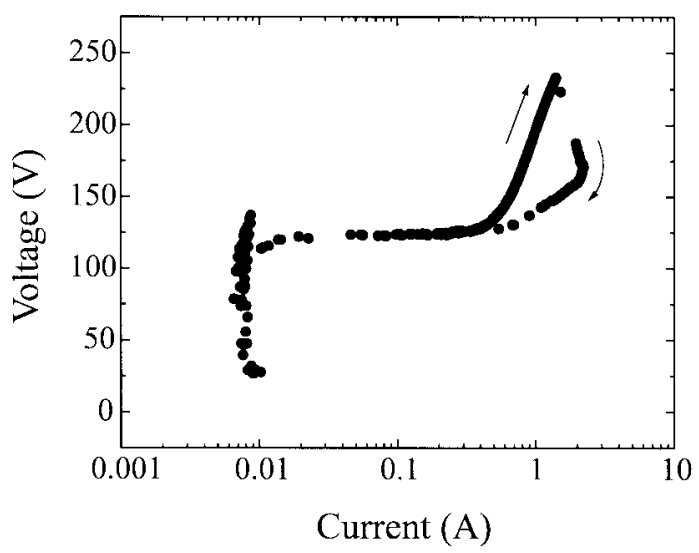

Fig. 15. Current-voltage characteristics of the atmospheric-pressure plasma jet $[60]$.

The ionized gas from the plasma jet exits through a nozzle, where it is directed onto a substrate a few millimeters downstream. Under typical operating conditions, the gas velocity is about $12 \mathrm{~m} / \mathrm{s}$ with the effluent temperature near $150^{\circ} \mathrm{C}$. So far, this source has been used to etch polyimide, tungsten, tantalum, and silicon dioxide [7], as well as to deposit silicon dioxide films by plasma-assisted chemical vapor deposition (CVD) [59].

Measurements with an impedance probe have revealed that the plasma jet exhibits properties typical of a low-pressure DC discharge [60]. In Fig. 15, the dependence of the root-

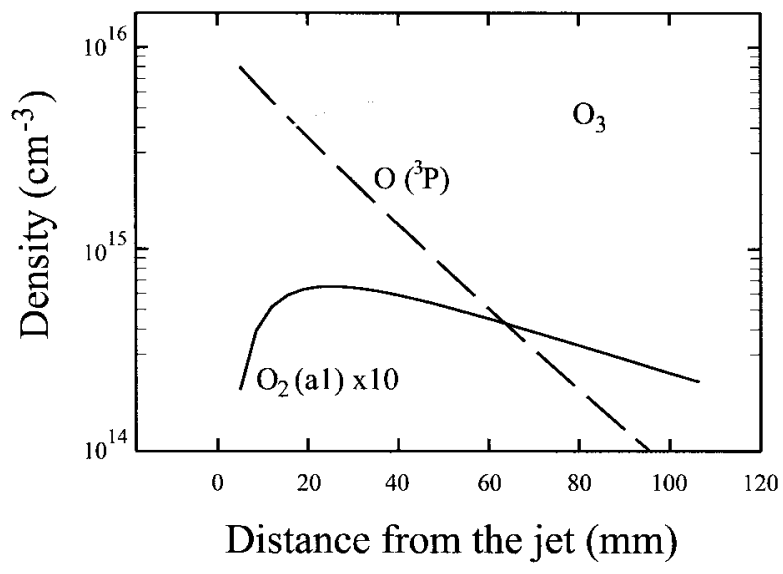

Fig. 16. Numerical simulation of the concentrations of species in the effluent of the plasma jet as a function of the distance from the nozzle in a $1.0 \%$ $\mathrm{O}_{2} / \mathrm{He}$ plasma at 760 torr [61].

mean-square voltage on the conductive current is shown for a pure helium plasma at 760 torr. At about $0.01 \mathrm{~A}$, breakdown occurs near $130 \mathrm{~V}$. Note that this breakdown voltage is significantly lower than that reported in Fig. 1 for a parallelplate discharge. Above spark breakdown, the voltage changes little with increasing current. Then at $0.5 \mathrm{~A}$, the voltage increases with current, until at $2.0 \mathrm{~A}$, arcing occurs and the voltage drops quickly. The $I-V$ curve for the plasma jet exhibits the same trends as a low-pressure DC discharge (cf. Fig. 2), including the "normal" and "abnormal" glow regions, and the same ranges of voltage and current (except that the voltage values are shifted down by a factor of three or four).

Langmuir probe measurements in the jet effluent indicate that the concentration of charged species is relatively low, on the order of $1 \times 10^{10} \mathrm{~cm}^{-3}$ [60]. However, inside the jet the electron density should be much higher, as suggested by the intense atomic lines observed in the optical emission spectrum. Based on the impedance measurements and the emission spectra, it is estimated that the electron temperature inside the plasma jet averages between $1-2 \mathrm{eV}$.

Jeong et al. [61] measured the ozone concentration in the effluent of the plasma jet at different distances from the nozzle and found that it varied from $2-5 \times 10^{15} \mathrm{~cm}^{-3}$, as shown in Fig. 16. Using these data as the basis for fixing the other species concentrations, a preliminary kinetic model was developed to determine the concentrations of $\mathrm{O}$ atoms and metastable oxygen molecules $\left(a^{1} \Delta_{g}\right)$ in the jet effluent. These results are also shown in the figure. The simulation predicts that the $\mathrm{O}$ atom concentration equals $8 \times 10^{15} \mathrm{~cm}^{-3}$ at the nozzle exit, and then gradually falls two orders of magnitude over a $10-\mathrm{cm}$ distance downstream. The concentration of metastable oxygen is about $2 \times 10^{13} \mathrm{~cm}^{-3}$ at the exit of the nozzle, then increases to a maximum at $25 \mathrm{~mm}$, and slowly drops off. The $\mathrm{O}$ atoms, and possibly the metastable $\mathrm{O}_{2}$, are believed to be the active species in polyimide etching and in the $\mathrm{SiO}_{2}$ CVD process [7], [59].

\section{COLD PlaSma TORCH}

A "cold" plasma torch was first described by Koinuma et al. [62] in 1992. A schematic of this source is shown in 


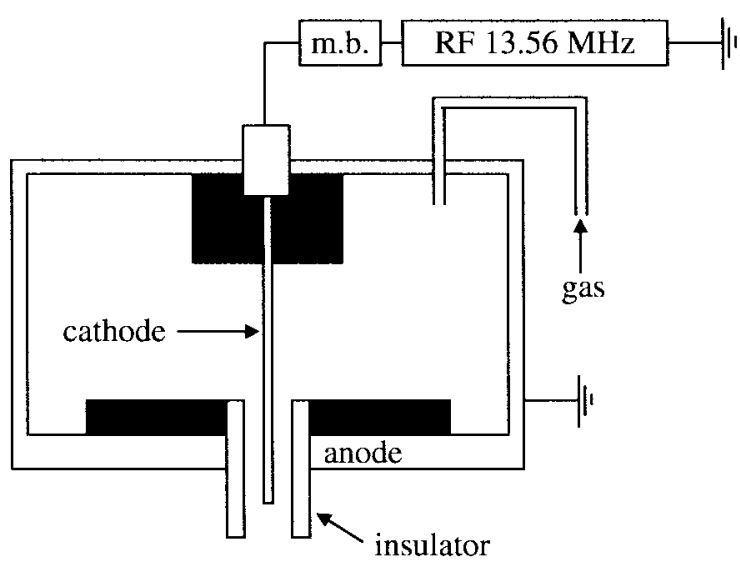

Fig. 17. Schematic of a cold plasma torch (m.b. = matchbox) [62].

TABLE I

Breakdown Voltages of the Plasma Discharges

\begin{tabular}{c|c}
\hline Source & $\mathrm{V}_{\mathrm{b}}(\mathrm{kV})$ \\
\hline Low-pressure discharge & $0.2-0.8$ \\
\hline Arc and plasma torch & $10-50$ \\
\hline Corona & $10-50$ \\
\hline Dielectric barrier discharge & $5-25$ \\
\hline Plasma jet & $0.05-0.2$ \\
\hline
\end{tabular}

Fig. 17. The powered electrode consists of a metal needle with a thickness of $1 \mathrm{~mm}$. This needle is inserted into a grounded metal cylinder. In addition, a quartz tube is placed between the cathode and anode, which makes this device resemble a dielectric barrier discharge. Mixtures of rare gases, $\mathrm{He}$ and $\mathrm{Ar}$, and other species are fed between the metal needle and quartz tube at flow velocities of about $5 \mathrm{~m} / \mathrm{s}$ at $200-400^{\circ} \mathrm{C}$. The gases are ionized and exit the source as a small jet. Koinuma and coworkers have employed the cold plasma torch in a number of materials processes, including silicon etching [62], photoresist ashing [63], deposition of $\mathrm{SiO}_{2}$, and $\mathrm{TiO}_{2}$ films [64]-[67], treatment of vulcanized rubber [68], and the production of fullerenes [69].

Koinuma and coworkers [69] measured the electron temperature in the plasma effluent with a Langmuir probe and found it to be between 1-2 eV depending on the gas composition.

\section{COMPARISON OF Plasma Sources}

Low-pressure plasma discharges are widely used in materials processing, because they have a number of distinct advantages: 1) low breakdown voltages; 2) a stable operating window between spark ignition and arcing; 3) an electron temperature capable of dissociating molecules $(1-5 \mathrm{eV})$, but a low neutral temperature; 4) relatively high concentrations of ions and radicals to drive etching and deposition reactions; and 5) a uniform glow over a large gas volume. It is instructive to compare atmospheric-pressure plasmas against these criteria, to see if any of these sources can match the performance of low-pressure discharges.

Shown in Table I are breakdown voltages for the different plasma sources. The plasma jet has a $V_{b}$ below that of a low-pressure discharge, whereas the other atmospheric-
TABLE II

Densities of Charge Species in the Plasma Discharges

\begin{tabular}{l|c}
\hline \multicolumn{1}{c|}{ Source } & Plasma density $\left(\mathrm{cm}^{-3}\right)$ \\
\hline Low-pressure discharge & $10^{8}-10^{13}$ \\
\hline Arc and plasma torch & $10^{16}-10^{19}$ \\
\hline Corona & $10^{9}-10^{13}$ \\
\hline Dielectric barrier discharge & $10^{12}-10^{15}$ \\
\hline Plasma jet & $10^{11}-10^{12}$ \\
\hline
\end{tabular}

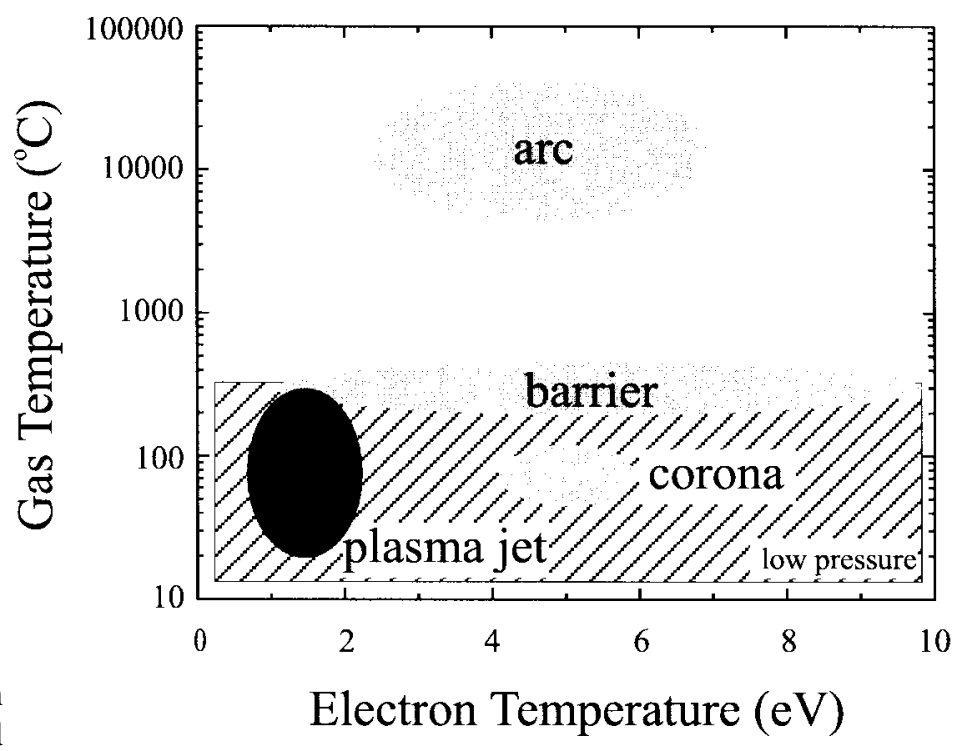

Fig. 18. Comparison of the gas and electron temperatures for different atmospheric-pressure plasmas versus low-pressure plasmas.

pressure plasmas have breakdown voltages above $10 \mathrm{kV}$. A comparison of the $I-V$ curves reveals that the corona and the plasma jet exhibit normal and abnormal glow regions that are characteristic of a weakly ionized plasma. However, the current in a corona is limited to below $10^{-4} \mathrm{~A}$, which is insufficient to ionize a reasonable volume of the gas.

Presented in Table II are the densities of charged species in the different plasma discharges. Except for the transferred arc and plasma torch, all the plasmas exhibit electron densities in the same range as a low-pressure discharge. However, in the corona and the dielectric barrier discharge, the plasma is restricted to a small region of space and is not available for uniformly treating large substrate areas. Recent results obtained in our laboratory indicate that the plasma jet can be scaled up to dimensions required in industrial processes [70].

Shown in Fig. 18 are the ranges of neutral and electron temperatures that apply to each plasma discharge. The plasma jet and corona clearly fall within the range commonly utilized in low-pressure plasma discharges. The electron temperature of the plasma jet is estimated to be between 1-2 eV. However, there is a sufficient population of electrons at energies high enough to dissociate many molecules, including $\mathrm{O}_{2}$ and $\mathrm{N}_{2}$ [70].

Listed in Table III are the average densities of oxygen ions, oxygen atoms, and ozone in the different atmospheric-pressure plasma discharges. Since the dielectric barrier discharge operates as a series of transient microarcs, it is difficult to 
TABLE III

Densities of Oxygen Species in the Plasma Discharges

\begin{tabular}{l|c|c|c}
\hline \multirow{2}{*}{ Source } & \multicolumn{3}{|c}{ Density $\left(\mathrm{cm}^{-3}\right)$} \\
\cline { 2 - 4 } & $\mathrm{O}^{+}, \mathrm{O}_{2}^{+}, \mathrm{O}^{-}$ & $\mathrm{O}$ & $\mathrm{O}_{3}$ \\
\hline Low-pressure discharge & $10^{10}$ & $10^{14}$ & $<10^{10}$ \\
\hline Arc and plasma torch & $10^{15}$ & $10^{18}$ & $<10^{10}$ \\
\hline Corona & $10^{10}$ & $10^{12}$ & $10^{18}$ \\
\hline Dielectric barrier & $10^{10}$ & $10^{12}$ & $10^{18}$ \\
\hline Plasma jet & $10^{12}$ & $10^{16}$ & $10^{16}$ \\
\hline
\end{tabular}

obtain time-averaged values for the reactive species. However, perusal of the literature suggests that the time averaged concentrations should be similar to those found in a corona. Also, the values shown for the plasma jet correspond to the gas in between the electrodes. In the downstream jet, the distribution of species changes as indicated in Fig. 16.

In the corona and dielectric barrier discharge, ozone is the main reaction product, whereas in the other plasmas, oxygen atoms represent a large fraction of the reactive species. In a low-pressure glow discharge the concentrations of ions and atoms are lower than in an atmospheric-pressure plasma. However, the impingement rate of these species on a substrate may be about the same in both cases, since the flux to the surface increases with decreasing pressure. Taking into account all the properties of the plasmas, it appears that the atmospheric-pressure plasma jet exhibits the greatest similarity to a low-pressure glow discharge. Consequently, this device shows promise for being used in a number of materials applications that are now limited to vacuum.

\section{REFERENCES}

[1] H. Schmid, B. Kegel, W. Petasch, and G. Liebel, "Low pressure plasma processing in microelectronics," in Proc. Joint 24th Int. Conf. Microelectronics (MIEL) and 32nd Symp. Devices Materials SD'96, Nova Gorcia, Slovenia, 1996, pp. 17-35.

[2] M. A. Lieberman and A. J. Lichtenberg, Principles of Plasma Discharges and Materials Processing. New York: Wiley, 1994.

[3] P. Fauchais and A. Vardelle, "Thermal plasmas," IEEE Trans. Plasma Sci., vol. 25, pp. 1258-1280, Dec. 1997.

[4] R. W. Smith, D. Wei, and D. Apelian, "Thermal plasma materials processing-Applications and opportunities," Plasma Chem. Plasma Process., vol. 9, no. 1, pp. 135S-165S, 1989.

[5] M. Goldman and R. S. Sigmond, "Corona and insulation," IEEE Trans. Elect. Insulation, vol. EI-17, no. 2, pp. 90-105, 1982.

[6] B. Eliasson and U. Kogelschatz, "Nonequilibrium volume plasma chemical processing," IEEE Trans. Plasma Sci., vol. 19, pp. 1063-1077, Dec. 1991.

[7] J. Y. Jeong, S. E. Babayan, V. J. Tu, J. Park, R. F. Hicks, and G. S. Selwyn, "Etching materials with an atmospheric-pressure plasma jet," Plasma Source Sci. Technol., vol. 7, no. 3, pp. 282-285, 1998.

[8] Y. P. Raizer, Gas Discharge Physics. New York: Springer-Verlag, 1991.

[9] M. I. Boulos, "Thermal plasma processing," IEEE Trans. Plasma Sci., vol. 19, pp. 1078-1089, Dec. 1991

[10] E. E. Kunhardt, "Electrical breakdown of gases: The prebreakdown stage," IEEE Trans. Plasma Sci., vol. PS-8, pp. 130-138, June 1980.

[11] R. Woo, "RF voltage breakdown and the Paschen curve," Proc. IEEE, vol. 62 , no. 4 , p. $521,1974$.

[12] J. M. Meek and J. D. Craggs, Electrical Breakdown of Gases. London, U.K.: Oxford Univ. Press, 1953.

[13] G. Francis, "The glow discharge at low pressure," in Encyclopedia of Physics, Gas Discharges II, vol. XXII, S. Flügge, Ed. Berlin, Germany: Springer-Verlag, 1956, pp. 53-208.

[14] W. Elenbaas, The High Pressure Mercury Vapor Discharge. Amsterdam, The Netherlands: North-Holland, 1951.

[15] E. Pfender, "Electric arcs and arc heaters," in Gaseous Electronics, vol. 1, M. N. Hirsh and H. J. Oskam, Eds. New York: Academic, 1978.
[16] M. Shibata, N. Nakano, and T. Makabe, "Effect of $\mathrm{O}_{2}\left(a^{1} \Delta_{g}\right)$ on plasma structures in oxygen radio frequency discharges," J. Appl. Phys., vol. 80, no. 11 , pp. 6142-6147, 1996.

[17] K. S. Klopovskii, A. M. Popov, A. T. Rakhimov, T. V. Rakhimov, and V. A. Feoktistov, "Self-consistent model of an $h f$ discharge at low pressure in an oxygen plasma," Plasma Phys. Rep., vol. 19, no. 7, pp. 473-477, 1993.

[18] G. S. Selwyn, "Spatially resolved detection of $\mathrm{O}$ atoms in etching plasmas by two-photon laser-induced fluorescence," J. Appl. Phys., vol. 60, no. 8, pp. 2771-2774, 1986.

[19] S. Ramakrishnan and M. W. Rogozinski, "Properties of electric arc plasma for metal cutting," J. Appl. Phys. D, vol. 30, pp. 636-644, 1997.

[20] V. A. Nemchinsky, "Dross formation and heat transfer during plasma arc cutting," J. Appl. Phys. D, vol. 30, pp. 2566-2572, 1997.

[21] D. R. Mac Rae, "Plasma arc process systems, reactors, and applications," Plasma Chem. Plasma Process., vol. 9, no. 1, pp. 85S-118S, 1989.

[22] W. H. Gauvin, "Some characteristics of transferred-arc plasmas," Plasma Chem. Plasma Process., vol. 9, no. 1, pp. 65S-84S, 1989.

[23] G. Laroche and M. Orfeuil, Plasma in Industry. Avon, France: Doppée Collection, 1989, p. 699

[24] J. Heberlein and E. Pfender, "Thermal plasma chemical vapor deposition," in Materials Science Forum, J. J. Pouch and S. A. Alterovitz, Ed. Aedermannsdorf, Switzerland: Trans. Tech. Publications Ltd., 1993, vol. 140-142, pp. 477-496.

[25] P. Fauchais, M. Vardelle, A. Vardelle, and L. Bianchi, "Plasma spray: Study of the coating generation," Ceram. Int., vol. 22, no. 4, pp. 295-303, 1996

[26] T. Yoshida, "The future of thermal plasma processing," Materials Trans., $J I M$, vol. 31, no. 1, pp. 1-11, 1990.

[27] Y. Chang, R. M. Young, and E. Pfender, "Silicon nitride synthesis in an atmospheric pressure convection-stabilized arc," Plasma Chem. Plasma Process., vol. 9, no. 2, pp. 277-289, 1989.

[28] N. Kubota, M. Ayabe, T. Fukuda, and M. Akashi, "Characterization of $\mathrm{TiO}_{2}$ thick films photoelectrodes prepared by the plasma-spray coating," Mater. Res. Soc., vol. 458, pp. 449-452, Dec. 1997.

[29] A. G. Cunha, M. T. D. Orlando, F. G. Emmerich, C. Larica, and E. M. Baggio-Saitovitch, "Optimization of $\mathrm{Yba}_{2} \mathrm{Cu}^{3} \mathrm{O}_{7}$ superconducting thick layers produced by plasma spray technique," Physica C, vol. 282-287, pp. 489-490, 1997.

[30] J. R. Fincke, W. D. Swank, and D. C. Haggard, "Plasma spray of alumina: Plasma and particle flow fields," Plasma Chem. Plasma Process., vol. 13, no. 4, pp. 579-600, 1993.

[31] Z. P. Lu, L. Stachowicz, P. Kong, J. Heberlein, and E. Pfender, "Diamond synthesis by thermal plasma CVD at 1 atm," Plasma Chem. Plasma Process., vol. 11, no. 3, pp. 387-394, 1991.

[32] Z. P. Lu, J. Heberlein, and E. Pfender, "Process study of thermal plasma chemical vapor deposition of diamond-Part I: Substrate material, temperature, and methane concentration," Plasma Chem. Plasma Process., vol. 12 , no. 1 , pp. $35-53,1992$.

[33] _ "Process study of thermal plasma chemical vapor deposition of diamond-Part II: Pressure dependence and effect of substrate pretreatment," Plasma Chem. Plasma Process., vol. 12, no. 1, pp. 55-69, 1992.

[34] J. M. Olson and M. J. Dawes, "Examination of the material properties and performance of thin-diamond film cutting tool inserts produced by arc-jet and hot filament chemical vapor deposition," J. Mater. Res., vol. 11, no. 7, pp. 1765-1775, 1996.

[35] S. K. Baldwin, Jr., T. G. Owano, and C. H. Kruger, "Growth rate studies of CVD diamond in an RF plasma torch," Plasma Chem. Plasma Process., vol. 14, no. 4, pp. 383-406, 1994.

[36] S. K. Baldwin, Jr., T. G. Owano, M. Zhao, and C. H. Kruger, "Enhanced deposition rate of diamond in atmospheric pressure plasma CVD: Effects of a secondary discharge," Diam. Relat. Mater., vol. 6, no. 2-4, pp. 202-206, 1997.

[37] L. Pawlowski and P. Fauchais, "Thermally sprayed coatings for electrical and electronic applications," in Materials Science Forum, J. J. Pouch and S. A. Alterovitz, Eds. Aedermannsdorf, Switzerland: Trans. Tech. Publications Ltd., 1993, vol. 140-142, pp. 497-520.

[38] S. Ramakrishnan, M. Gershenzon, F. Polivka, T. N. Kearney, and M. W. Rogozinski, "Plasma generation for the plasma cutting process," IEEE Trans. Plasma Sci., vol. 25, pp. 937-946, Oct. 1997.

[39] C. H. Kruger, "Nonequilibrium effects in thermal plasma chemistry," Plasma Chem. Plasma Process., vol. 9, no. 4, pp. 435-443, 1989.

[40] C. H. Kruger, T. G. Owano, and C. O. Laux, "Experimental investigation of atmospheric pressure nonequilibrium plasma chemistry," IEEE Trans. Plasma Sci., vol. 25, pp. 1042-1051, Oct. 1997.

[41] H. Kim and S. H. Hong, "Comparative measurements on thermal plasma jet characteristics in atmospheric and low pressure plasma sprayings," 
IEEE Trans. Plasma Sci. vol. 23, pp. 852-859, Oct. 1995.

[42] H. Hoffmann, " $\mathrm{O}^{-}$-ion radiation in the spectrum of an oxygen arc plasma," J. Quant. Spectrosc. Radiat. Transf., vol. 21, no. 2, pp. 163-180, 1979.

[43] R. C. Weast, Ed., CRC Handbook of Chemistry and Physics. Boca Raton, FL: CRC Press, 1988.

[44] L. B. Loeb, Electrical Coronas. Berkeley/Los Angeles, CA: Univ. California Press, 1965.

[45] R. S. Sigmond and M. Goldman, "Corona discharge physics and applications," in Electrical Breakdown and Discharges in Gases, E. E. Kunhardt and L. H. Luessen, Eds. New York: Plenum, 1983, pp. 1-64.

[46] J. S. Chang, P. A. Lawless, and T. Yamamoto, "Corona discharge processes," IEEE Trans. Plasma Sci., vol. 19, pp. 1152-1166, Dec. 1991.

[47] M. Goldman and N. Goldman, "Corona discharges," in Gaseous Electronics, vol. 1, M. N. Hirsh and H. J. Oskam, Eds. New York: Academic, 1978, pp. 219-290.

[48] L. Gresser, R. Peyrous, N. Spyrou, and B. Held, "Influence of a polymer sample on wire-to-plane corona discharge regimes," in Proc. XXIII Int. Conf. Phenomena Ionized Gases, Toulouse, France, 1997, pp. 180-181.

[49] E. Neagu, "The influence of annealing time on thermally stimulated discharge current of corona-charged polymers," Mater. Lett., vol. 21 , no. 1, pp. 119-125, 1994

[50] M. R. Madani and P. K. Ajmera, "Characterization of silicon oxide films grown at room temperature by point-to-plane corona discharge," J. Electron. Mater., vol. 22, no. 9, pp. 1147-1152, 1993.

[51] S. M. Sayedi, L. M. Landsberger, and M. Kahrizi, "Electrical characterization of thin $\mathrm{SiO}_{2}$ films created by negative-point oxygen corona discharge processing," in Proc. 1996 Conf. Electr. Comput. Eng., Calgary, Canada, 1996, pp. 64-67.

[52] F. Carreño and E. Bernabeu, "On wire-to-plane positive corona discharge," J. Appl. Phys. D, vol. 27, no. 10, pp. 2136-2144, 1994

[53] F. Pontiga, C. Soria, and A. Castellanos, "Electrical and chemical model of negative corona in oxygen at atmospheric pressure," J. Electrostatics, vol. 40-41, pp. 115-120, June 1997.

[54] B. Eliasson and U. Kogelschatz, "Modeling and applications of silent discharge plasmas," IEEE Trans. Plasma Sci., vol. 19, pp. 309-323, Apr. 1991.

[55] U. Kogelschatz and B. Eliasson, "The applications of silent discharges" (in German), Physikalische Blätter, vol. 52, no. 4, pp. 360-362, 1996.

[56] J. Salge, "Plasma-assisted deposition at atmospheric pressure," Surf. Coat. Technol., vol. 80, no. 1-2, pp. 1-7, 1996

[57] J. R. Roth and Y. Ku, "Surface cleaning of metals in air with a one atmosphere uniform glow discharge plasma," in Abstracts IEEE Int Conf. Plasma Sci., Madison, WI, 1995, p. 251.

[58] R. Thyen, A. Weber, and C.-P. Klages, "Deposition of $\mathrm{SiO}_{x}$ thin films by corona discharge at atmospheric pressure," in Proc. 12th Int. Conf. Gas Discharges Applicat., Greifswald, Germany, 1997, vol. 1, pp. 144-148.

[59] S. E. Babayan, J. Y. Jeong, V. J. Tu, J. Park, G. S. Selwyn, and R. F. Hicks, "Deposition of silicon dioxide films with an atmosphericpressure plasma jet," Plasma Source Sci. Technol., vol. 7, no. 3, pp. 286-288, 1998.

[60] J. Park, J. Y. Jeong, R. F. Hicks, and G. S. Selwyn, submitted for publication.

[61] J. Y. Jeong, S. E. Babayan, V. J. Tu, J. Park, R. F. Hicks, and G. S. Selwyn, unpublished results.

[62] H. Koinuma, H. Ohkubo, T. Hashimoto, K. Inomata, T. Shiraishi, A. Miyanaga, and S. Hayashi, "Development and application of a microbeam plasma generator," Appl. Phys. Lett., vol. 60, no. 7, pp. 816-817, 1992

[63] K. Inomata, H. Koinuma, Y. Oikawa, and T. Shiraishi, "Open air photoresist ashing by a cold plasma torch: Catalytic effect of cathode material," Appl. Phys. Lett., vol. 66, no. 17, pp. 2188-2190, 1995.

[64] K. Inomata, H. Ha, K. A. Chaudhary, and H. Koinuma, "Open air deposition of $\mathrm{SiO}_{2}$ film from a cold plasma torch of tetramethoxysilane$\mathrm{H}_{2}-\mathrm{Ar}$ system," Appl. Phys. Lett., vol. 64, no. 1, pp. 46-48, 1994.

[65] H. Ha, K. Inomata, and H. Koinuma, "Plasma chemical vapor deposition of $\mathrm{SiO}_{2}$ on air-exposed surfaces by cold plasma torch," J. Electrochem. Soc., vol. 142, no. 8, pp. 2726-2730, 1995.

[66] H. Ha, M. Yoshimoto, H. Koinuma, B. Moon, and H. Ishiwara, "Open air plasma chemical vapor deposition of highly dielectric amorphous TiO 2 films," Appl. Phys. Lett., vol. 68, no. 21, pp. 2965-2967, 1996.

[67] H. Ha, B. K. Moon, T. Horiuchi, T. Inushima, and H. Koinuma, "Structure and electric properties of $\mathrm{TiO}_{2}$ films prepared by cold plasma torch under atmospheric pressure," Mater. Sci. Eng., vol. B41, no. 1, pp. 143-147, 1996

[68] B. Lee, Y. Kusano, N. Kato, K. Naito, T. Horiuchi, and H. Koinuma, "Oxygen plasma treatment of rubber surface by the atmospheric pressure cold plasma torch,” Jpn. J. Appl. Phys., vol. 36, no. 5A, pp. 2888-2891.
[69] K. Inomata, N. Aoki, and H. Koinuma, "Production of fullerenes by low temperature plasma chemical vapor deposition under atmospheric pressure," Jpn. J. Appl. Phys., vol. 33, no. 2A, pp. L197-L199, 1994.

[70] S. E. Babayan, J. Y. Park, J. Y. Jeong, A. Schütze, G. S. Selwyn, and R. F. Hicks, unpublished results.

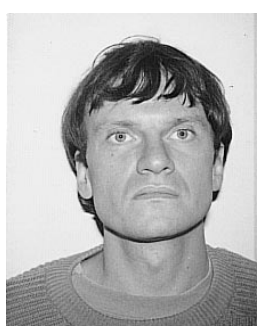

Andreas Schütze was born in Oberhausen, Germany, in 1963. He received the Diplom (M.S.) degree in physics from the University of Duisburg, Germany, in 1993 and the Dr.-Ing. (Ph.D.) degree in mechanical engineering, in 1997, from the University of Braunschweig, Germany.

In 1993, he joined the Fraunhofer-Institute FhGIST of surface engineering and thin films in Braunschweig, Germany. Since 1997, as a Grantee from the Deutsche Forschungsgemeinschaft (DFG), he has been working in the Department of Chemical Engineering at the University of California, Los Angeles, where his research is focused on the development of atmospheric-pressure plasma jets.

Dr. Schütze is a member of the German Physics Society.

James Y. Jeong was born in 1970, in Seoul, Korea. Currently, he is currently working toward the Ph.D. degree in the Department of Chemical Engineering, University of California, Los Angeles.

$\mathrm{He}$ is working on the research and development of atmospheric-pressure plasma jets and especially on the spectroscopy and modeling of atmosphericpressure plasmas.

Mr. Jeong is a member of the American Vacuum Society, the Electrochemical Society, and Tau Beta Pi.

Steven E. Babayan was born in 1974, in Huntington Beach, CA. He is currently working toward the Ph.D. degree in the Department of Chemical Engineering, University of California, Los Angeles.

$\mathrm{He}$ is working on the research and development of atmospheric-pressure plasma jets and especially on the plasma CVD deposition of various thin films.

Mr. Babayan is a member of the American Vacuum Society and the American Institute of Chemical Engineers.

Jaeyoung Park was born in Seoul, Korea, in 1970. He received the B.S. degree in physics from the Korea Advanced Institute of Science and Technology, Taejeon, Korea, and the M.S. and Ph.D. degrees in astrophysical sciences from Princeton University, Princeton, NJ.

$\mathrm{He}$ is currently working in the Los Alamos National Laboratory, Los Alamos, NM, as a Post-Doctoral Researcher. His general research interests are in plasma-neutral interactions and plasma spectroscopy.

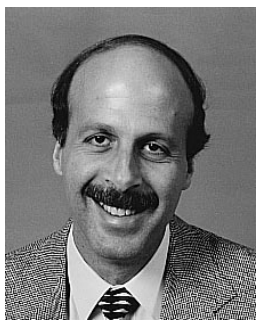

Gary S. Selwyn received the B.S. degree in chemistry from New York State University, Albany, in 1974, and the Ph.D. degree in chemical physics from University of California, Berkeley, in 1979.

From 1979 to 1980 , he did post-doctoral research at the University of Canterbury, Christchurch, New Zealand, and at the U.S. Naval Research Laboratory, Washington, DC, from 1980 to 1982 as an NRC Post-Doctoral Fellow. From 1982-1994, he worked first as a Staff Scientist at the IBM E. Fishkill Development Facility and then as a Research Manager at the IBM Watson Research Center. From 1994 to 1996, he was an Adjunct Professor in the Department of Chemical Engineering at the University of California, Los Angeles. He is currently working in the Los Alamos National Laboratory, Los Alamos, NM, and studies the chemistry and physics of plasmas used in materials processing. 


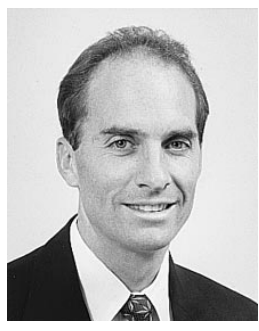

Robert F. Hicks was born in Middletown, NJ, in 1955. He received the B.S. and Ph.D. degrees in chemical engineering from the University of Delaware, Newark, in 1977 and the University of California at Berkeley, in 1984, respectively.

From 1983 to 1985, he was a Research Engineer at W. R. Grace and Co., Columbia. He then joined the Department of Chemical Engineering of the University of California, Los Angeles, in 1985. He was promoted to Full Professor in 1996. His research interests are in the physics and chemistry of semiconductor materials processes, including chemical vapor deposition and plasma processing.

Dr. Hicks is a member of the American Institute of Chemical Engineers, American Chemical Society, American Vacuum Society, and the Materials Research Society. 